\title{
Control of Cardiovascular Risk Factors in the Semi-Urban Population of Guéoul in Senegal
}

\author{
Mame Madjiguène Ka, Serigne Cheikh Tidiane Ndao, Kana Sonia Babaka, Abu Bakr Fafa Cissé, \\ Abdallah Ould Béchir, Isabelle Kouamé, Malick Ndiaye, Dior Diagne Sow, Moussa Kane, \\ Bouna Diack, Alassane Mbaye, Abdoul Kane
}

Cardiology Unit of Grand Yoff General Hospital, Dakar, Senegal

Email:madjigueneka@gmail.com

How to cite this paper: Ka, M.M., Ndao, S.C.T., Babaka, K.S., Cissé, A.B.F., Béchir, A.O., Kouamé, I., Ndiaye, M., Sow, D.D., Kane, M., Diack, B., Mbaye, A. and Kane, A. (2021) Control of Cardiovascular Risk Factors in the Semi-Urban Population of Guéoul in Senegal. World Journal of Cardiovascular Diseases, 11, 69-81.

https://doi.org/10.4236/wjcd.2021.111009

Received: December 28, 2020

Accepted: January 25, 2021

Published: January 28, 2021

Copyright $\odot 2021$ by author(s) and Scientific Research Publishing Inc. This work is licensed under the Creative Commons Attribution International License (CC BY 4.0).

http://creativecommons.org/licenses/by/4.0/ (c) (i) Open Access

\begin{abstract}
Introduction: Cardiovascular disease is a global public health problem. In Africa, they are increasingly common, however, data on the control of cardiovascular risk factors in the general Senegalese population are rare. The aim of this work was to assess the level of control of cardiovascular risk factors in semi-urban areas in the municipality of Guéoul in Senegal. Patients and methods. This is a cross-sectional, descriptive and exhaustive survey carried out from 3 November to 3 December 2012 among the population aged at least 35 years and living for more than 6 months in the commune of Gueoul. It was conducted using the WHO STEPS approach to study the prevalence of cardiovascular risk factors and assess their level of control. We looked at clinical history, lifestyle, and anthropometric data. Blood pressure was measured at both arms and fasting blood samples were taken for blood glucose, cholesterol and triglycerides. Results. We examined 1.411 subjects (1052 women) averaging $48.5 \pm 12.7$ years of age. The main cardiovascular risk factors were dyslipidemia (61\%), sedentary (56\%), abdominal obesity (53.9\%), high blood pressure (46.4\%) and diabetes (7.2\%). Dyslipidemia was known in 22 subjects, 6 of whom were on treatment with dyslipidemia control in 1 subject (16.7\%). Hypertension was known in 266 subjects. Of these, 205 subjects were prescribed medical treatment, 26 of whom were well controlled (12.7\%). The level of hypertension control was lower in subjects at high cardiovascular risk $(\mathrm{p}=0.0001)$ and those with a family history of hypertension $(\mathrm{p}=0.001)$. The male gender $(\mathrm{p}=0.24)$, the short duration of progression of hypertension $(\mathrm{p}$ $=0.95)$ and the noncompliance of the diet $(p=0.176)$ were not significantly associated with poor control of hypertension. In diabetics, subjects on oral antidiabetic drugs had met fasting glucose targets in $65.5 \%$ of cases according to the recommendations of the American Diabetes Association and in $58.6 \%$ according to those of the International Diabetes Federation $(p=0.0001)$. Age,
\end{abstract}


regular physical activity and insulin treatment were not significantly related to fasting blood sugar control. Conclusion: Our study found inadequate control and high prevalence of cardiovascular risk factors in the general Senegalese population. This situation could be a cause of aggravation of cardiovascular diseases in Senegal and should promote to improve their management.

\section{Keywords}

Cardiovascular Risk Factors, Control, Hypertension, Africa

\section{Introduction}

Cardiovascular diseases are a real public health problem around the world and particularly in Africa, where there is an epidemiological transition. These pathologies are most often secondary to atherosclerosis, the occurrence of which is correlated with the existence of cardiovascular risk factors (CVRF). A survey carried out in Brazzaville in 2008 on 1636 people revealed an obesity rate of $20 \%$, a prevalence of hypertension at $43 \%$ and diabetes at $13 \%$ [1]. In our country, there are several surveys including one carried out in Saint-Louis in 2010 [2], another in Darou Mousty in 2011 and this one in Gueoul in 2013, all revealing high prevalence of CVRF. The management and control of these factors are therefore proving to be a major challenge in order to stop the burden of cardiovascular diseases.

However, data regarding management and control of overall cardiovascular risk in the general African population remains insufficient. Regarding their control under treatment, most surveys were either carried out in diabetics or focused on studying one or two factors.

This fact delays the development of clear strategies to fight against this scourge. In this work, we aimed to assess the level of control over the CVRF in a municipality in Senegal. It may help to elaborate adapted strategies to our context by acting in the barriers to optimal control of CVRF.

\section{Methodology}

\subsection{Study Framework and Type of Study}

The survey took place in the semi-rural commune of Guéoul, which is $169 \mathrm{~km}$ from Dakar. Guéoul covers an area of $12.96 \mathrm{~km}^{2}$.

We conducted a cross-sectional, descriptive and comprehensive study over a period of 1 month, from November 03 to December 3, 2012. It was carried out using the WHO's STEPwise approach.

\subsection{Population Selection and Variables Studied}

We included Senegalese subjects of both genders (except pregnant women), that 
have 35 years of age or older and living in one of the neighborhoods of the commune for at least 6 months, and having given their informed consent. At the end of the study, 1.411 subjects were included out of the 1.500 expected and included in our study population. Our data collection tool consisted of the World Health Organization (WHO) questionnaire using the STEPwise approach for monitoring risk factors for chronic diseases. The variables studied were:

- socio-demographic variables: age, gender, education level, socio-professional category

- clinical variables: personal and family history of high blood pressure, diabetes, dyslipidemia, cardiovascular disease (heart disease, stroke), lifestyle habits (smoking, alcohol, physical inactivity).

- biomedical variables: measures of blood pressure, heart rate, size, weight, waist circumference, blood samples for the dosage of the blood fasting blood sugar, total and HDL cholesterol, triglycerides and LDL cholesterol calculation.

Blood pressure was measured using an electronic sphygmomanometer OMRON M6. Each subject has been systematically taken two consecutive blood pressure levels performed by the same team-appointed technician. These blood pressures were taken after 10 minutes of rest, in a sitting position, at both arms. The highest values were retained.

The weighing was carried out in kilograms $(\mathrm{kg})$ with a branded scale OMRON placed on a stable, flat surface in a lightly dressed person without shoes. Height in centimeters was measured using a portable measuring rod, in individuals not shod and not wearing a hat.

The measurement of the waist circumference (umbilical perimeter) was done by a tape meter standard nine, applied directly to the skin. This measurement was carried out according to the axillary line, halfway between the lower base of the last rib and the iliac crest; measurement is taken only once at a close of $1 \mathrm{~cm}$.

A blood sample was collected from all individuals included in the study after a 12-hour fasting period.

The analysis of biological data (blood glucose, total cholesterol, HDL cholesterol, triglyceridemia) was performed using a BTS 350 spectrophotometer.

LDL-cholesterol was calculated from The Friedwald Formula (LDL-C $(\mathrm{g} / \mathrm{l})=$ Total cholesterol (g/l) - HDL-cholesterol (g/l) - Triglyceridemia (g/l)/5) when the triglyceridemia was lower than $4.5 \mathrm{~g} / \mathrm{l}$.

Another fast blood glucose test was performed for all individuals with first fasting blood glucose dose $\geq 1.26 \mathrm{~g} / \mathrm{l}$ in the absence of symptoms.

The data collected was captured through a questionnaire developed with the Epi Info software version 7. The analysis of the database used the Analysis module of the SPSS 18 software (Statistical Package of Social Science). The graphics were made using the Excel software for the 2010 MS Office.

The analysis plan was as follows:

- The descriptive study of the different variables was carried out with the calculation of the proportions for categorical variables, and position and dispersal parameters for quantitative variables. 
- The bi-varied analysis was carried out through the tests of the Khi 2 (Pearson and Yates) for comparisons of proportions. The difference was statistically judged significant for a $5 \%$ threshold.

- Multivariate analysis used binary logistic regression. A variable was retained (statistically significant difference) when probability (p) was less than 0.05 (5\%). The Odds Ratio (Odds Report) allowed us to quantify the level of dependence of significant variables.

\subsection{Definition of Variables}

- Sedentary lifestyle was defined by lack of physical activity or the presence of moderate physical activity or walking less than 30 minutes a day for at least 5 days a week, according to the WHO [3].

- Inadequate consumption of fruits and vegetables was defined by the consumption of less than 5 fruits or vegetables per day [4].

- Active smoking was considered as cardiovascular risk factor when it was current or discontinued for less than three years [5].

- Excessive alcohol consumption was defined by taking more than 2 drinks per day (or 14 drinks per week) in women and more than 3 drinks per day (or 21 drinks per week) in the men [5].

- Abdominal obesity was defined by the International Diabetes Federation (IDF) by a waist circumference greater than $94 \mathrm{~cm}$ in men and $80 \mathrm{~cm}$ in women [6] and by the National Cholesterol Education Program (NCEP) by a waist circumference greater than $102 \mathrm{~cm}$ in men and $88 \mathrm{~cm}$ in woman [7].

- The body mass index (BMI) was calculated by the ratio of weight (in $\mathrm{kg}$ ) to the square of the waist (in $\mathrm{m}$ ). The individual was said to be lean if BMI less than $18 \mathrm{~kg} / \mathrm{m}^{2}$, BMI between 18 and $25 \mathrm{~kg} / \mathrm{m}^{2}$, overweight between 25 and 30 $\mathrm{kg} / \mathrm{m}^{2}$ BMI and obese if BMI greater than or equal to $30 \mathrm{~kg} / \mathrm{m}^{2}$.

- Hypertension was defined by blood pressure of $140 / 90 \mathrm{mmHg}$ or more [8] and/or a known history of high blood pressure. Controlling numbers under treatment corresponded to a blood pressure below that threshold.

- Diabetes mellitus was defined by a fasting blood sugar level above or equal $1.26 \mathrm{~g} / \mathrm{L}$ twice and/or a known history of diabetes. Blood sugar control was defined by a fasting blood glucose of $<1.08 \mathrm{~g} / \mathrm{l}$ depending on the IDF [9] or $<1.21 \mathrm{~g} / \mathrm{l}$ depending on American Diabetes Association ADA [10].

- Dyslipidemia: it was defined by the presence of a known history of dyslipidemia and/or one or more of the following abnormalities: hypertriglyceridemia $>1.5 \mathrm{~g} / \mathrm{l}$, LDL-cholesterol $>1.6 \mathrm{~g} / \mathrm{l}$, HDL-cholesterol $<0.5 \mathrm{~g} / \mathrm{l}$ in women and $<0.4 \mathrm{~g} / \mathrm{l}$ in humans $[11]$.

\section{Results}

\subsection{General Characteristics of the Population}

At the end of the survey, 1411 subjects were examined out of the 1500 expected. Age population was 48 years and 5 months, with extremes of 35 and 95 years. 
The 35 - 44 age group was the most represented in the population. Also, 58.8\% of men $(n=211)$ and $36.8 \%$ of women were over the age of $50(n=387)$. The female gender was predominant and accounted for $74.6 \%$ of the population with a sex ratio of 0.34 .

The most common CVRF was dyslipidemia with prevalence of $61.1 \%$. High blood pressure affected $46.4 \%$ of the population, diabetes prevalence was $7.2 \%$. Sedentary living was found in $56.1 \%$ of cases, overall obesity (BMI) in $13 \%$, metabolic syndrome in $19.8 \%$ (IDF) and $13.1 \%$ (NCEP ATP III), smoking in $2.5 \%$ of cases, excessive alcohol consumption in $0.28 \%$ of cases. Cardiovascular risk according to Framingham was low in $54.5 \%$ of cases, intermediate in $2.6 \%$ and high in $42.8 \%$. This cardiovascular risk according to Framingham was high for $70.1 \%$ of diabetics, $62.2 \%$ of hypertensives, $49.6 \%$ of people with dyslipidemia. In Table 1, the characteristics of our study population are presented.

Table 1. Characteristics of our study population.

\begin{tabular}{|c|c|c|}
\hline Characteristics & Number (n) & Percentage (\%) \\
\hline \multicolumn{3}{|c|}{ Gender } \\
\hline Men & 359 & 25.4 \\
\hline Women & 1052 & 74.6 \\
\hline \multicolumn{3}{|c|}{ Age } \\
\hline $35-44$ & 658 & 46.6 \\
\hline $45-54$ & 331 & 23.5 \\
\hline $55-64$ & 237 & 16.8 \\
\hline $65-74$ & 129 & 9.1 \\
\hline $75-84$ & 38 & 2.7 \\
\hline$\geq 85$ & 18 & 1.3 \\
\hline \multicolumn{3}{|c|}{ Prevalence of cardiovascular risk factors } \\
\hline Hypertension & 654 & 46.4 \\
\hline Diabetes & 102 & 7.2 \\
\hline Dyslipidemia & 862 & 61.1 \\
\hline Tobacco & 35 & 2.5 \\
\hline Alcohol & 9 & 0.6 \\
\hline Sedentary lifestyle & 791 & 56.1 \\
\hline Obesity (BMI) & 183 & 13 \\
\hline \multicolumn{3}{|l|}{ Metabolic syndrome } \\
\hline IDF & 279 & 19.8 \\
\hline NCEP-ATP III & 185 & 13.1 \\
\hline \multicolumn{3}{|c|}{ Cardiovascular risk (Framingham score) } \\
\hline Low & 723 & 54.5 \\
\hline Intermediate & 35 & 2.6 \\
\hline High & 568 & 42.8 \\
\hline
\end{tabular}




\subsection{Level of Control of Major CVRF}

\subsubsection{High Blood Pressure}

Of the 266 known hypertensive subjects, 205 or $77 \%$ were taking a medical treatment, with inhibitors of the conversion enzyme being the most commonly prescribed alone or in association with diuretics. Only $12.7 \%$ of these patients treated $(n=26)$ were controlled. Subjects on diuretics alone were best controlled (33.3\%), however, the difference between therapeutic classes was not statistically significant $(\mathrm{p}=0.72)$.

Hypertensive patients with no family history of hypertension were significantly better controlled (51.89\%) than those with family history $(61.29 \%)(\mathrm{p}=$ 0.001 , OR $=1.47)$. The level of control decreased significantly with cardiovascular risk according to Framingham $(\mathrm{p}<0.0001)$. Figure 1 shows the level of control of hypertension according to cardiovascular risk calculated by Framingham equation.

\subsubsection{Diabetes}

Among known diabetic subjects, less than half $(41 \%)$ were regularly under treatment. Only $27.6 \%$ of these diabetics on treatment in our study fasting blood glucose targets according to the IDF and $32.9 \%$ according to the ADA.

Age, socio-professional activity, regular physical activity, following a diabetic diet, and insulin treatment were not significantly related to fasting blood glucose control. $65.5 \%$ and $58.6 \%$ of patients on ADO had met their glycemic goals according to the ADA and the IDF ( $\mathrm{p}<0.0001)$.

\subsubsection{Dyslipidemia}

Seven of the 22 (or $31.8 \%$ ) individuals with dyslipidemia were treated. However only one of them met the targets under treatment; he was on a low fat and cholesterol diet treatment. Four of the 5 patients not controlled, however, associated the drugs with the diet.

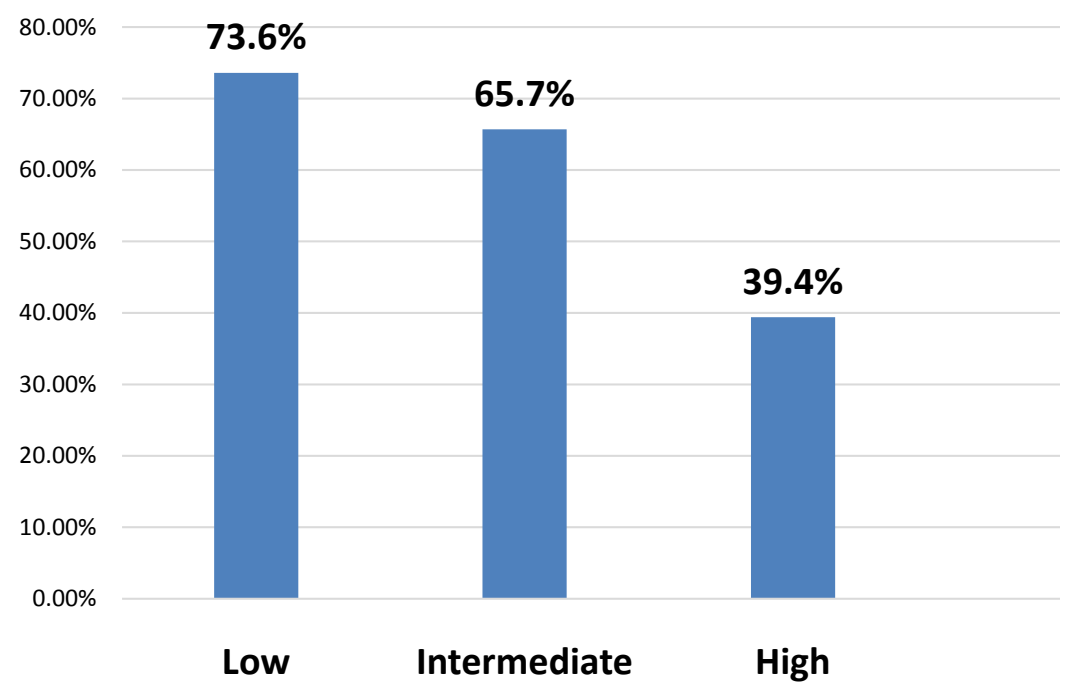

Figure 1. Level of control of hypertension according to cardiovascular risk. 


\section{Discussion}

In Africa, many surveys conducted in the general population described the CVRF prevalence. Even though they were interested in the control under treatment, they were usually done only for one CVRF or were conducted in hospital. Our study involved 1.411 people, out of the 1.500 expected, representing more than $95 \%$ of Guéoul's population.

In our population, a clear majority of women (74.6\%) was observed with a sex ratio of 0.34. Other studies, such as that conducted in St. Louis in 2010 (sex ratio of 0.45 ) [2], show this same trend. This predominance of women could be explained mainly by the exodus and widespread emigration in Gueoul among men, who would also be indisposed by their work. Probably for the same reasons, $58.8 \%$ of men were over 50 years of age compared to $36.8 \%$ for women.

Among the 205 patients on medical treatment (constituting $77 \%$ of hypertensive persons), 26 patients or $12.7 \%$ were controlled. This control of the hypertension is low compared to the results recorded in Tlemcen in semi-urban areas (23.6\%) [12], and in Burkina Faso's outpatients treated in a cardiology ward (45.8\%). But it is higher than that found in Brazzaville in the general population of $0.7 \%$ [1]. In developed countries, a survey conducted in Ontario revealed a control rate of $66 \%$ [13]; another in the United States showed a rate of 56\% [13]. The trend in these developed countries is that of better control under treatment.

Comparing these results, it appears that the control of the blood pressure values under treatment would depend on several factors:

- health structure in charge of treatment (general hospital, specialist service, health district),

- countries' level of health development (quality of health care secondary prevention and above all, availability and purchasing power of drugs, the level of information patients have about their pathology),

- intrinsic factors to patients (global cardiovascular risk, associated treatments, age).

Diabetics were aware of their status in $74.5 \%$ of cases $(n=76)$, while $25.5 \%$ were screened at the time of the survey $(n=26)$. Among known diabetic subjects, less than half (41\%) were regularly under treatment. However, only $27.6 \%$ of diabetics on treatment in our study had reached the fasting blood glucose targets according to the IDF and $32.9 \%$ according to the ADA. A better fasting blood glucose control was noted by Ndour Mbaye in St. Louis (33.3\% according to the IDF and 39.6\% according to the ADA) [14] and in the Diab Care-Senegal survey in Dakar (31.3\% according to the IDF and $52.6 \%$ according to the ADA) [15].

$65.5 \%$ and $58.6 \%$ of patients on ADO had met their glycemic goals according to ADA and IDF respectively ( $\mathrm{p}<0.0001$ ). These results are difficult to interpret due to a small number of patients on regular treatment on the one hand, and on the other hand because the dosage of the glycated hemoglobin is the reference method for the evaluation of diabetes control. 
Of those with dyslipidemia, 97.44\% were unaware of their status $(n=840)$. Six of the known individuals with dyslipidemia were on treatment and only one of them was controlled. In St. Louis [2], 30.8\% of these patients with their status was under treatment but none were controlled. In France, the survey Mona Lisa revealed that $47 \%$ were on treatment, but $27.7 \%$ of high-level cardiovascular risk subjects alone had met the goals according to the AFSSAPS [16].

The management of dyslipidemia is a problem in many countries, both in the screening and achievement of therapeutic goals, despite the recommendations on it. Factors of poor control of dyslipidemia could not be determined in our study with certainty, due to the low rates of treated patients. However, there are some parameters that tend to influence this level of control: quality of the medical technical platform, continuous training of general cardiovascular risk, the patient's overall cardiovascular risk, the level of information on pathology and therapeutic observance.

Our study has, however, experienced limitations: the absence of the dosage of the glycated hemoglobin that better reflects the level of diabetes control or the small percentage of treated patients making it difficult to assess the effectiveness of various treatments.

\section{Conclusion}

Our study found that cardiovascular risk factors are generally poorly controlled in a high-prevalence environment, making it precarious for the cardiovascular prognosis of this Gueoul population. This type of work should be extended to other parts of Senegal, with wider cohorts. This would allow us to better assess the overall management of CVRF, identify barriers to optimal control, in order to be able to put in place appropriate and effective control strategies.

\section{Conflicts of Interest}

The authors declare no conflicts of interest regarding the publication of this paper.

\section{References}

[1] Levisse, P., Mughnetsyan, V. and Kessy, G.S. (2009) Epidemiological Study Based on Mass Screening for Diabetes, Hypertension and Android Obesity in Brazzaville (Congo), 2008. Medecine des Maladies Metaboliques, 3, 438-441. https://doi.org/10.1016/S1957-2557(09)72413-7

[2] Pessinaba, S., et al. (2010) Prevalence Survey of Cardiovascular Risk Factors in the General Population in St. Louis (Senegal). Annales de Cardiologie et d Angéiologie (Paris), 62, 253-258.

[3] Organisation Mondiale de la Santé (2014) Questionnaire mondial sur la pratique d'activités physiques (GPAQ) - Guide pour l'analyse. 26 p.

http://www.who.int/chp/steps

[4] Organisation Mondiale de la Santé, Département des maladies chroniques et de la promotion de la santé (2014) L'approche "STEPwise" de l'OMS pour la surveillance 
des facteurs de risque des maladies chroniques. http://www.who.int/chp/steps

[5] Attias, D., Besse, B. and Lellouche, N. (2013-2014) Cardiologie vasculaire. Editions Vernazobres-Grego, Paris, 663.

[6] Alberti, K.G., Zimmet, P. and Shaw, J. (2005) The Metabolic Syndrome-A New Worldwide Definition. The Lancet, 366, 1059-1062. https://doi.org/10.1016/S0140-6736(05)67402-8

[7] National Cholesterol Education Program (NCEP) Expert Panel on Detection, Evaluation, and Treatment of High Blood Cholesterol in Adults (Adult Treatment Panel III) (2002) Third Report of the National Cholesterol Education Program (NCEP) Expert Panel on Detection, Evaluation, and Treatment of High Blood Cholesterol in Adults (Adult Treatment Panel III) Final Report. Circulation, 106, 3143-3421. https://doi.org/10.1161/circ.106.25.3143

[8] World Health Organization (1999) International Society of Hypertension Guidelines for the Management of Hypertension. Journal of Hypertension, 17, 151-183. https://doi.org/10.1097/00004872-199917020-00001

[9] International Diabetes Federation Clinical Guidelines Task Force (2006) Global Guideline for Type 2 Diabetes: Recommendations for Standard, Comprehensive, and Minimal Care. Diabetic Medicine, 23, 579-593. https://doi.org/10.1111/j.1464-5491.2006.01918.x

[10] American Diabetes Association (2008) Clinical Practices Recommendations 2008. Standards of Medical Care in Diabetes 2008. Diabetes Care, 31, 12-54. https://doi.org/10.2337/dc08-S012

[11] Grundy, S.M., Cleeman, J.I., Daniels, S.R., Donato, K.A., Eckel, R.H., Franklin, B.A., et al. (2005) Diagnosis and Management of the Metabolic Syndrome: An American Heart Association/National Heart, Lung, and Blood Institute Scientific Statement (Executive Summary). Circulation, 112, 285-290. https://doi.org/10.1161/CIRCULATIONAHA.105.169405

[12] Yahia-Berrouiguet, A., Benyoucef, M., Meguenni, K. and Brouri, M. (2009) Enquête sur la prévalence des facteurs de risque de maladies cardio-vasculaires à Tlemcen (Algérie). Medecine des Maladies Metaboliques, 3, 316-319. https://doi.org/10.1016/S1957-2557(09)74761-3

[13] Organisation Mondiale de la Santé (2014) Contrôle de l'hypertension sous médication: une analyse comparative des enquêtes nationales dans 20 pays. Bull World Health Organ, 92, 10-19. https://doi.org/10.2471/BLT.13.121954

[14] NDour Mbaye, M., Niang, K., Sarr, A., et al. (2011) Aspects épidémiologiques du diabète au Sénégal: Résultats d'une enquête sur les facteurs de risque cardiovasculaire dans la ville de Saint-Louis. Medecine des Maladies Metaboliques, 5, 659-664. https://doi.org/10.1016/S1957-2557(11)70343-1

[15] Ndour Mbaye, M., Sarr, A., Diop, S.N., et al. (2011) DiabCare Sénégal: Une enquête sur la prise en charge du diabète au Sénégal. Medecine des Maladies Metaboliques, 5, 85-89. https://doi.org/10.1016/S1957-2557(11)70200-0

[16] Wagner, A., Arveiler, D., Ruidavets, J.B., Cottel, D., Bongard, V., Dallongeville, J., Ferrieres, J., Amouyel, P. and Haas, B. (2008) Bulletin Epidémiologique Hebdomadaire, 49-50, 483-486. 


\section{Appendix: Survey Sheet}

Date of the investigation:

Team No:

Questionnaire number:

A.1. General information on the interviewee

Subject identification number:

How long have you lived in Guéoul? 6 months 12 months $>12$ months

District: Phone:

Last name

First Name:

Gender: man woman Age:

Have you been educated? Yes No If yes, in which language?

French English Arabic Other (specify):

What level of education have you attained?

Primary school 01

school secondary 02

High school 03

University 04

Post-University diploma 05

What is your professional activity?

State employee (civil servant) $01 \quad$ Housewife 05

Private employee 02

Student 06

Self-employed worker 03

Retired 07

Volunteer 04

Unemployed 08

Socio-economic data

Household size:

Average monthly income:

Source of income: Agricultural $01 \quad$ Non-Agricultural 02

\section{A.2. Behavioral measures}

\section{A. Tobacco consumption}

1) do you currently use tobacco? Yes No If no go to question 5 If yes which type: Cigarettes Cigars Smoking Pipes Outlet Chew

2) Do you consume it daily?

Yes No

3) How long ago did you start using daily?

4) How much tobacco do you consume on average each day?

5) Have you ever used tobacco in the past?

Yes No

If yes, specify the duration and quantity

6) Are you exposed to tobacco smoke? Yes No

If so, daily sometimes rarely

B. Alcohol consumption

1) Do you have an alcoholic drink? Yes No

If yes, specify the type: Beer Wine Liquor Other (specify)

the frequency? (Number of days per week)

2) How many drinks do you have on average per day?

\section{Nutrition}


What do you think about the importance of eating fruit and vegetables?

Very good

Good

Don't know

1) During a week, on how many days do you consume fruit?

2) How many fruits do you eat/day? $\begin{array}{lllllll}0 & 1 & 2 & 3 & 4 & \geq 5\end{array}$

If so, which fruit?

Reason given for insufficient fruit consumption: Lack of awareness the cost physical accessibility preference beliefs, dislike Other

3) In a week, how many days do you consume vegetables?

4) How much raw and/or cooked vegetables do you eat/day? Specify which ones

Raw: $\quad \begin{array}{llllll}0 & 1 & 2 & 3 & 4 & \geq 5\end{array}$

Cooked: $\quad \begin{array}{llllll}0 & 1 & 2 & 3 & 4 & \geq 5\end{array}$

Reason given for insufficient consumption of vegetables: Lack of knowledge the cost preference beliefs, dislike physical accessibility Other

5) Number of meals per day:

6) What do you eat in the morning:

7) What do you eat at noon:

8) What do you eat in the evening:

9) Do you consume broths (cubes, others)? $\quad$ Ye $\quad$ No

If Yes How many per day?

10) Do you combine broths and cooking salt?

Yes No

\section{Physical activity}

1) Do you participate in any physical activity? Yes No

If No pass to question 2)

If yes which type: Running Lifting weights Walking quickly

Swimming bike Others (specify)

- How many days per week do you do the activity physical?

- How much time do you spend on it per day? In minutes

2) Reason given for the non-practice of sporting activity

\section{A.3. Background}

A. History of high blood pressure

1) Do you know if you are hypertensive? Yes No

2) If so, for how long?

3) Are you on treatment? No Yes regularly Yes irregularly

- Drug treatment Yes No If yes, specify the type.........

- Traditional treatment No Yes (if yes, specify.........................)

- Have you been prescribed a special diet No Yes (specify: ............)

- Monthly cost of treatment?

- Who pays? myself another person medical insurance 
- Who treats? 1 District 2 Hospital 3 Others

\section{B. History of diabetes}

1) Do you know if you have diabetes? Yes No

2) If so, for how long?

3) Are you on treatment? No Yes regularly Yes irregularly

- Drug treatment Yes No

If yes, specify: Insulin: Yes No

Oral antidiabetics: Yes No Other

- Traditional treatment: No Yes (if yes specify: ......................)

- Have you been prescribed a special diet No Yes

(if yes specify:

C. History of dyslipidemia

1) Do you know if you have excessive cholesterol? Yes

No

2) If so, for how long?

3) Are you receiving treatment? Yes No

- Drug treatment Yes No

- Traditional treatment No Yes (if yes, specify: .......................)

- Have you been prescribed a special diet? No Yes (specify: .............)

If yes, specify the type

- Monthly cost of treatment?

- Who pays? myself another person medical insurance

- Who treats? 1 District 2 Hospital 3 Others

D. Healthy lifestyle

1) Consumption or treatment of excessive alcohol consumption Yes No

2) Advice or treatment for weight loss: Yes No

3) Advice or treatment to quit smoking Yes No

4) Advice on starting or doing more physical activity Yes No

E. Others

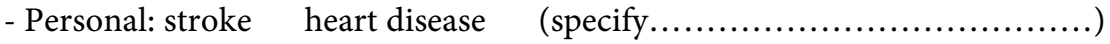

Kidney disease Others (specify)

- Familial: hypertension Diabetes stroke coronary artery disease

Kidney disease sudden death in a 1st degree relative

\section{A.4. Clinic}

1) Symptoms

Do you have the following symptoms? Dyspnoea Chest pain

Palpitations Chest pain when walking Headache Dizziness

Tinnitus Visual blur Polyuria Polydipsia

Polyphagia lower limbs oedema Facial puffiness Weight loss

Others

2) Physical measurements

Weight $(\mathrm{kg})$ : Height $(\mathrm{m})$ BMI $\left(\mathrm{kg} / \mathrm{m}^{2}\right)$

Waist size $(\mathrm{cm})$ :

Cardiac frequency:. Tower of hip (cm): 
Blood pressure Right arm ( $\mathrm{mm} \mathrm{Hg}$ ):

Systolic Pressure Index (IPS):

Right: $<0.9$

Left: $<0.9$

normal

$>1.2$

Cardiovascular examination: Normal Abnormal

Specify the anomaly...

Renal examination: lumbar contact renal sloshing

Urinary strips:

Hematuria: $\quad 0+++$ plus

Proteinuria: $0+++$ plus

Leukocyturia: $0+++$ plus

Nitrites: $\quad 0+++$ plus

Urinary density:

If proteinuria $\geq++$, do proteinuria/creatinuria

\section{3) Biology}

Fasting blood sugar $(\mathrm{g} / \mathrm{l})$ : Blood creatinine $(\mathrm{mg} / \mathrm{l})$ :

Cholesterol total $(\mathrm{g} / \mathrm{l})$ : HDL-Cholesterol $(\mathrm{g} / \mathrm{l})$ :

LDL-Cholesterol (g/l): Triglyceridemia $(\mathrm{g} / \mathrm{l})$ :

Glycated hemoglobin (\%): Homocysteinemia:

Creatininuria: Proteinuria:

Uricemia:

Left arm (mm Hg): normal $>1.2$

Uricemia: 